\title{
Evaluating the effect of donor anxiety levels and lifestyle characteristics on the activation of platelet concentrates
}

\author{
Soner Yılmaz ${ }^{1}$, İbrahim Eker ${ }^{2}$, Elif Elçi ${ }^{3}$, Aysel Pekel ${ }^{4}$, Rıza Aytaç Çetinkaya ${ }^{5}$, Aytekin Ünlü ${ }^{6}$, \\ Cengizhan Açıkel ${ }^{7}$ İsmail Yaşar $\mathrm{Avcl}^{8}$ \\ ${ }^{1}$ Regional Blood Center, Health Science University, Gulhane Training and Education Hospital, Ankara, ${ }^{2}$ Department of Pediatric \\ Hematology, Afyon Kocatepe University, Afyon, ${ }^{3}$ Department of Hematology, ${ }^{4}$ Department of Allergy and Immunology, Health \\ Science University, Gulhane Training and Education Hospital, Ankara, ${ }^{5}$ Department of Infectious Disease, Health Science University, \\ Sultan Abdulhamid Han Training and Education Hospital, Istanbul, ${ }^{6}$ Department of General Surgery, Health Science University, \\ Gulhane Training and Education Hospital, Ankara, Turkey, ${ }^{7}$ Clinical Research International Ltd, Cologne, Germany, ${ }^{8}$ Department of \\ Infectious Disease and Clinical Microbiology, Health Science University, Gulhane Training and Education Hospital, Ankara, Turkey
}

p-ISSN 2287-979X / e-ISSN 2288-0011 https://doi.org/10.5045/br.2019.54.4.262 Blood Res 2019;54:262-268.

Received on July 1, 2019

Revised on September 3, 2019

Accepted on October 1, 2019

\section{Correspondence to}

Soner Yilmaz, M.D.

Regional Blood Center, Health Science University, Gulhane Training and Education Hospital, Ankara 06018, Turkey E-mail: drsoneryilmaz@gmail.com

(C) 2019 Korean Society of Hematology

\section{Background}

Smoking, alcohol use, performing regular physical exercise, dietary habits, and anxiety level may cause platelet activation. We aimed to evaluate the anxiety levels, smoking status, alcohol intake, and sportive habits of donors, and determine their impact on the quality of apheresis-platelets.

\section{Methods}

State and Transient Anxiety Inventory (STAI) was used to determine the level of donors' anxiety. STAI has two subscales: S-anxiety scale (STAI-I) and T-anxiety scale (STAI-II), each comprising 20 questions rated on a 4-point Likert scale. Data on smoking, alcohol consumption, and performing regular physical exercise were obtained from a questionnaire filled out before donation. Flow cytometric analysis was used to quantify activated platelets.

Results

The STAI-I level of 86 participants was normal, while that of 12 was higher. No significant difference was found in the active platelet absolute count $\left[1.8 \times 10^{11}(2.7)\right.$ and $1.4 \times 10^{11}$ (1.3), respectively; $P=0.665$ ] between donors with normal STAI-I levels and those with higher STAI-I levels. Of 98 donors, 42 had normal STAI-II levels, while 56 had higher STAI-II levels. No significant difference was found in the active platelet absolute count $\left[2.3 \times 10^{11}\right.$ (3.1) and $1.5 \times 10^{11}(2.3)$, respectively; $P=0.224$ ] between donors with normal STAI-II levels and those with higher STAI-II levels. Platelet counts of individuals who perform regular physical exercise were significantly higher than those of individuals who did not perform regular physical exercise $\left(6.3 \pm 1.4 \times 10^{11}\right.$ vs. $\left.5.5 \pm 1.4 \times 10^{11}\right)$.

\section{Conclusion}

The quality of apheresis platelets is not affected by anxiety levels and lifestyle characteristics of blood donors. There is no need to organize apheresis blood donor pool considering with these subjects.

Key Words Platelet, Apheresis, Anxiety

\section{INTRODUCTION}

Platelet transfusion has an important role in the treatment of patients with thrombocytopenia or serious platelet function disorder and in the prevention of bleeding. Platelet concentrates can be obtained from donated whole blood or by apheresis from a single donor [1]. The quality of platelets diminishes during storage. Factors such as thromboxane genetic polymorphism, donation frequency, and use of nonsteroidal anti-inflammatory drugs (NSAIDs) and acetyl salicylic acid preparations may disrupt the functions of platelets 
in concentrates [2]. Moreover, recent studies have reported that anxiety, smoking, and dietary habits (especially alcohol and caffeine intake) may either activate platelets or cause alterations in platelet functions [3]. Studies on apheresis-platelet donors focused only on the factors that affect their decision to donate blood rather than their impact on the overall quality of platelet products $[4,5]$.

In this study, we aimed to evaluate the anxiety levels, smoking and alcohol intake habits, and performing regular physical exercise behaviors of donors. We also aimed to analyze the possible associations of these factors on the quality of apheresis-platelet concentrates by total platelet counts and absolute count of active platelets.

\section{MATERIALS AND METHODS}

\section{Procedure}

After ethical committee approval, the prospective study was conducted at the Gulhane Regional Blood Bank and Education Center. The suitability for blood donation was determined after completion of the Blood Donor Information and Inquiry forms, in accordance with the National Blood and Blood Products Guide [6]. Afterward, the venous blood samples were collected from suitable donors into K2-EDTA (7.2 mg; $4.0 \mathrm{~mL}$; BD, Erembodegem, Belgium) tubes. The analysis of whole blood was carried out using Sysmex XP-300 (Sysmex Corporation, Kobe, Japan) hematology analyzer. Donors with hemoglobin values $<13.5 \mathrm{~g} / \mathrm{dL}$ and platelet count more than the $150-500 \times 10^{9} / \mathrm{L}$ range were excluded from the study.

Power analysis was performed using G-Power 3.1 with the following specifications: a Type I error rate of $\alpha=0.05$, statistical power at $80 \%$, and effect size $\geq 0.50$. The study was initially conducted in 100 participants who stated that they did not have previous psychological disorders. All participants were selected among male donors since the study was executed in a military hospital and the vascular structures of the female candidates were not suitable for apheresis. Two persons, whose blood samples were not sufficient for another flow cytometry analysis, were excluded, and the study was completed with 98 participants. Before the apheresis was performed, all participants were informed about the procedure by the same psychologist and were assessed using the State and Trait Anxiety Inventory I and II (STAI-I, State Anxiety Inventory; STAI-II, Trait Anxiety Inventory). At least 150 minutes of moderate-intensity physical exercise or at least 75 minutes of vigorous-intensity physical exercise performed throughout the week was considered as regular physical exercise [7]. Donors who smoked every day or occasionally were considered smokers [8]. Donors who started to consume alcohol at any time of life and continued to consume alcohol were considered as alcohol drinkers [9].

\section{Application of STAI-I and STAI-II}

STAI-I and STAI-II were developed by Spielberger et al. in 1970 [10]. STAI-I is used to determine how the individual feels about himself/herself at a certain moment and under certain circumstances, while the STAI-II is used to determine how the individual feels himself/herself independent from the state that she/he is involved in and from the conditions. STAI-I generally provides information about ones feelings, which are experienced at that moment, while STAI-II is designed to measure the frequency of how a person "generally feels" anxious $[11,12]$. Both scales consisted of 20 multiple-choice items. Donors stated their agreement with each item on a Likert scale ranging from 1 (not at all) to 4 (very much so).

Both STAI-I and STAI-II determine the two types of expressions: direct expressions (which denote negative emotions) and reverse expressions (which denote positive feelings). These expressions are indicated in items $1,2,5,8$, $10,11,15,16,19$, and 20 in STAI-I, and in items 21, 26, 27, 30, 33, 36, and 39 in STAI-II. After calculating the total intensity of direct and reverse expressions separately, the total intensity value of the reverse expressions is subtracted from the total intensity value of direct expressions [13]. The scores obtained from both scales vary theoretically between 20 and 80 . A score of $>40$ indicated high levels of anxiety [14].

\section{Apheresis procedure and flow cytometry analysis}

The procedure was performed using Trima Accel system v6.0 (Terumo BCT, Lakewood, CO, USA). Trima Accel is an online apheresis system, which automatically isolates and collects the platelets, plasma, and erythrocytes. The instrument has the features necessary to monitor and control the extra corporal circulation in order to collect the reliable and effective product. A platelet-plasma red blood cell (RBC) hose set (LRS Platelet, Plasma, RBC Set for Trima Accel; ref. no. 80400; Terumo BCT) was used with the instrument in the study. During the apheresis procedure, citrate-dextrose solution, Solution A (ref. no. 6525; Kansuk, Turkey), was continuously added as an anticoagulant. After the completion of the procedure, $5 \mathrm{~mL}$ of platelet concentrates was taken from the sampling section of the apheresis set and was placed in two Eppendorf tubes. One of the sample tubes was placed in the hematology analyzer to determine the platelet count. The total number of platelets in the concentrates was calculated from the volume and platelet count [15]. The second sample tube was used to determine platelet activation markers. The parameters to be considered were marked on the beaded tubes (BD Trucount tubes, BD Biosciences, San Jose, CA, USA). CD41a (GPIIb/IIIa), CD42a, CD42b (GPIb), CD62P [other names include GMP-140, p-selectin, and platelet activation dependent granule-external membrane protein (PADGEM)], and CD45 antibodies were immediately added into the $50 \mu \mathrm{L}$ sample in the amounts given in the user guide (all antibodies obtained from Biosciences) [16]. All the contents were mixed carefully and then were incubated in the dark room at room temperature for 20 minutes. At the end of incubation, 400-800 $\mu \mathrm{L}$ CellFix solution (Benelux $\mathrm{NV}, \mathrm{BD}$, Erembodegem, Belgium) was added in order to fix the cells and was mixed carefully. The mixture was incubated in a dark room at room temperature for 15 minutes 
and then kept in the dark at a temperature of $2-8^{\circ} \mathrm{C}$.

The dyed platelets were analyzed using the FACSDiva software, BD FACSCanto II (BD Immunocytometry Systems, San Jose, CA, USA) model, within 1 hour. A total of 20,000 cells were counted. Total platelet count and absolute platelet count were calculated using the beaded tubes. Accordingly, the absolute active platelet count was determined using the following formula:

Absolute count of active platelets=50,650 (Trucount bead count) $\times$ active platelet percentage/trucount bead percentage

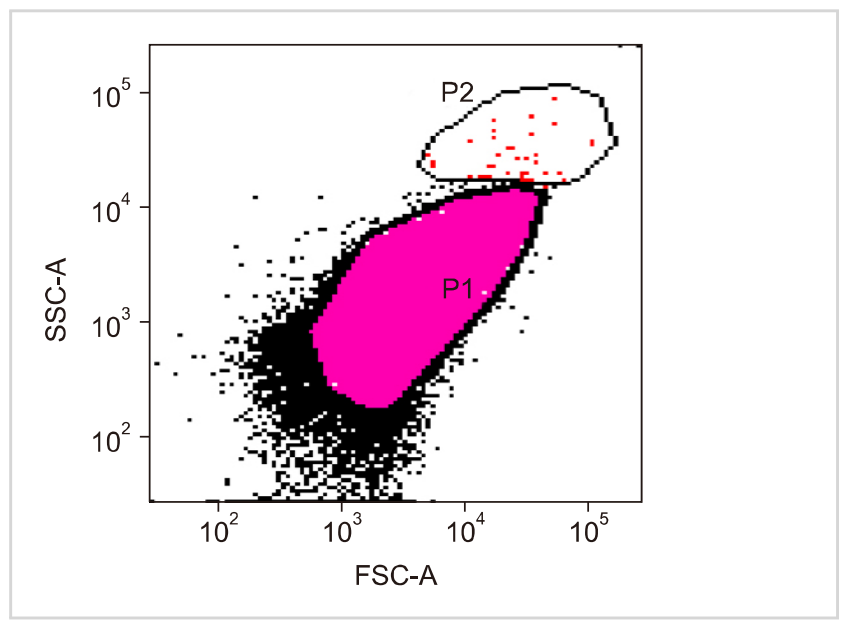

Fig. 1. Platelet population (P1) and trucount bead percentage (P2).
Platelet size tends to vary $(0.5-5 \mu \mathrm{m})$, and they show a very wide scattering in the forward scatter (FSC) and side scatter (SSC) dot plots. Therefore, FSC-SSC PMT voltage and gain settings were regulated logarithmically in order to obtain more concentrated appearance. When FSC is taken to $\mathrm{x}$ axis and SSC to $\mathrm{y}$ axis, the small cells, with minimum granule content, show a scattering close to zero point. These cells were identified as the platelets based on the aforementioned relevant indicators (Figs. 1, 2).

\section{Statistical analysis}

SPSS for Windows 22.0 was used (IBM, Armonk, NY, USA) in the statistical analysis. Qualitative variables were presented as numbers and percentages, while quantitative variables were presented as mean \pm standard deviation, minimum, and maximum. Continuous variables with non-normal distribution were expressed as median and interquartile ranges (IQR). Normality was assessed using the KolmogorovSmirnov test. The Mann-Whitney U test was used to compare independent variables, which included STAI-I and STAI-II levels (normal/higher), performing regular physical exercise (yes/no), smoking (yes/no), and alcohol consumption (yes/no). The correlation between the values from STAI-I and STAI-II and data related to the apheresis-platelet product quality was evaluated using Spearman's correlation analysis. A $P$-value of 0.05 or less was considered significant.
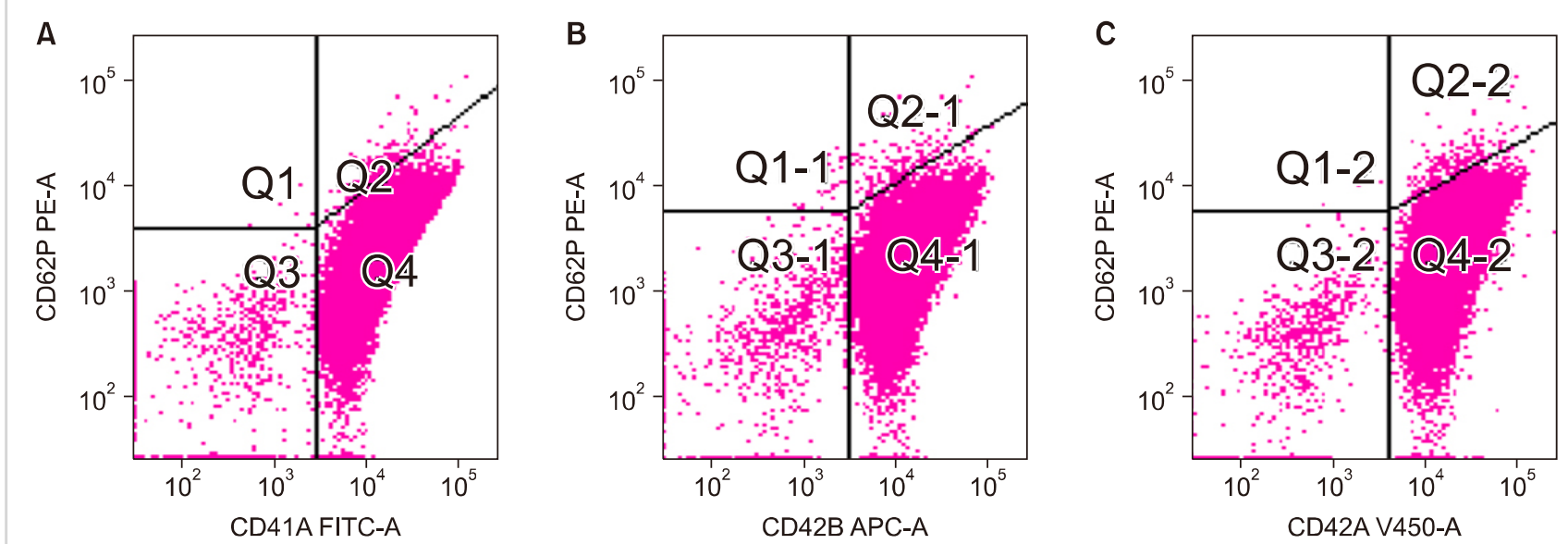

A Q2 (active platelet zone): CD41A-positive and CD62P-positive platelets Q3 (non-platelet cells zone): CD41A-negative and CD62P-negative cells Q4 (non-active platelet zone): CD41A-positive and CD62P-negative platelets

B Q2-1 (active platelet zone): CD42B-positive and CD62P-positive platelets Q3-1 (non-platelet cells zone): CD42B-negative and CD62P-negative cells Q4-1 (non-active platelet zone): CD42B-positive and CD62P-negative platelets

C Q2-2 (active platelet zone): CD42A-positive and CD62P-positive platelets Q3-2 (non-platelet cells zone): CD42A-negative and CD62P-negative cells Q4-2 (non-active platelet zone): CD42A-positive and CD62P-negative platelets

Fig. 2. Flow cytometry analysis of platelet populations. 
Table 1. Comparison of data on the quality of apheresis platelet product according to the participants' sporting habits, smoking status, and alcohol consumption status $(\mathrm{N}=98)$.

\begin{tabular}{|c|c|c|c|c|c|c|c|c|c|}
\hline \multirow{3}{*}{$\begin{array}{l}\text { Quality parameters of } \\
\text { apheresis platelets }\end{array}$} & \multicolumn{9}{|c|}{ Lifestyle characteristics } \\
\hline & \multicolumn{2}{|c|}{$\begin{array}{l}\text { Performing regular } \\
\text { physical exercise }\end{array}$} & \multirow{2}{*}{$P$} & \multicolumn{2}{|c|}{ Smoking } & \multirow{2}{*}{$P$} & \multicolumn{2}{|c|}{ Alcohol intake } & \multirow{2}{*}{$P$} \\
\hline & $\begin{array}{c}\text { Yes } \\
(\mathrm{N}=29)\end{array}$ & $\begin{array}{c}\text { No } \\
(\mathrm{N}=69)\end{array}$ & & $\begin{array}{c}\text { Yes } \\
(N=46)\end{array}$ & $\begin{array}{c}\text { No } \\
(\mathrm{N}=52)\end{array}$ & & $\begin{array}{c}\text { Yes } \\
(N=13)\end{array}$ & $\begin{array}{c}\text { No } \\
(\mathrm{N}=85)\end{array}$ & \\
\hline $\begin{array}{l}\text { Total platelet count, } \\
\text { median }(\mathrm{IQR}) \times 10^{11}\end{array}$ & $5.9(2.5)$ & $5.5(0.9)$ & 0.030 & $5.6(1.7)$ & $5.4(0.9)$ & 0.233 & $5.5(0.8)$ & $6.3(2.9)$ & 0.349 \\
\hline $\begin{array}{l}\text { Absolute count of } \\
\text { active platelet, } \\
\text { median (IQR) } \times 10^{11}\end{array}$ & $1.7(1.8)$ & $1.9(3)$ & 0.978 & $2(2.4)$ & $1.6(2.9)$ & 0.649 & $1.6(2.3)$ & $2.7(2.8)$ & 0.476 \\
\hline
\end{tabular}

Abbreviation: IQR, interquartile range.

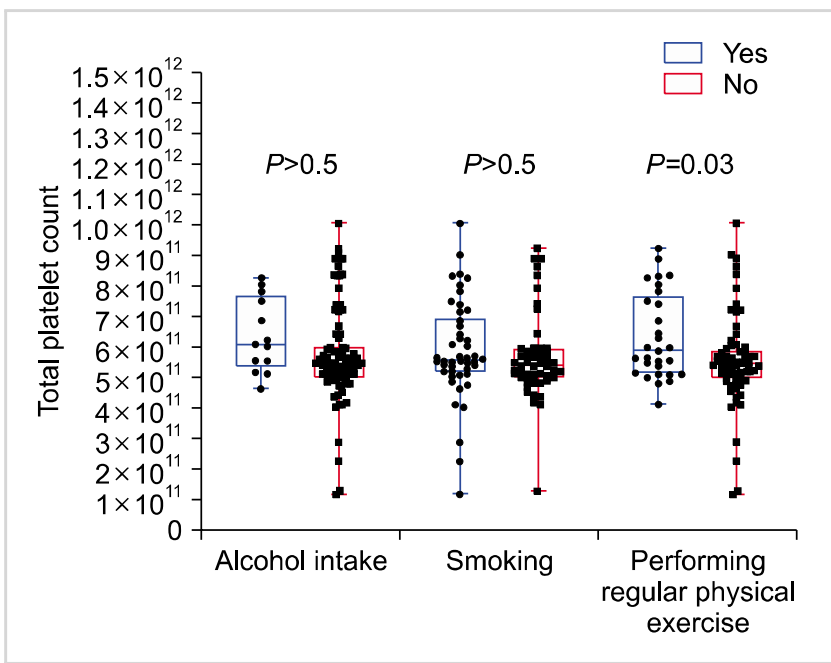

Fig. 3. Comparison of data on the total platelet count according to performing regular physical exercise, smoking and alcohol intake status of participants $(\mathrm{N}=98)$.

\section{RESULTS}

Approximately 59.1\% (58/98) of the participants donated whole blood, while $17.3 \%$ (17/98) donated apheresis-platelet. Since most of the participants were military service personnel from the Turkish Armed Forces and military students, the mean age was 24.6 years (min-max, 19-38).

The mean STAI-I and STA-II scores were $26.9 \pm 5.9\left(\mathrm{~min}^{-}\right.$ $\max , 20-46)$ and $34.8 \pm 6.3$ (min-max, 16-55), respectively. The STAI-I level of 86 participants was normal, while that of 12 was higher. No significant difference was found in the median value of total platelet count $\left[5.5 \times 10^{11}(1.1)\right.$ and $5.3 \times 10^{11}(1.4)$, respectively; $\left.P=0.237\right]$ and active platelet absolute count $\left[1.8 \times 10^{11}(2.7)\right.$ and $1.4 \times 10^{11}(1.3)$, respectively; $P=0.665$ ] in the apheresis-platelet products between donors with normal STAI-I levels and those with higher STAI-I levels.

The STAI-II level of 42 out of 98 donors was normal, while that of 56 was higher. No significant difference was

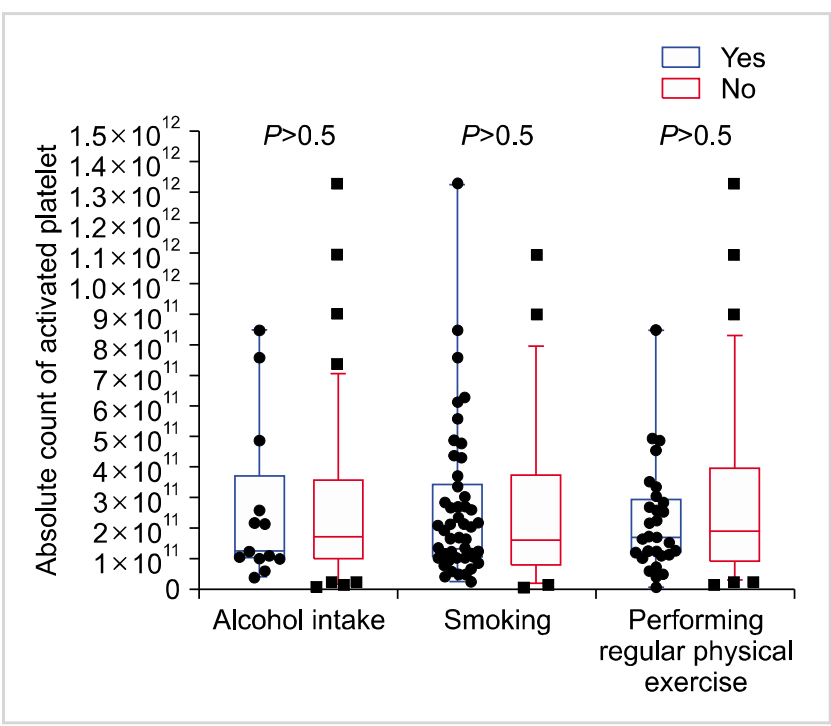

Fig. 4. Comparison of data on absolute count of activated platelets according to performing regular physical exercise, smoking and alcohol intake status of participants $(\mathrm{N}=98)$.

found in the median value of total platelet count $\left[5.5 \times 10^{11}\right.$ (2) and $5.5 \times 10^{11}(1.1)$, respectively; $\left.P=0.119\right]$ and active platelet absolute count $\left[2.3 \times 10^{11}(3.1)\right.$ and $1.5 \times 10^{11}(2.3)$, respectively; $P=0.224]$ in the apheresis-platelet products between donors with normal STAI-II levels and those with higher STAI-II levels.

Approximately 29.5\% (29/98) of the participants stated that they performed regular physical exercise; moreover, $46.9 \%(46 / 98)$ of the participants were smokers, while $53.1 \%$ (52/98) were non-smokers. Approximately 86.8\% (85/98) of the participants were not alcohol drinkers. No significant difference was found in the quality parameters between donors who smoked and those who consumed alcohol. The median value of total platelet count of the apheresis-platelet product was higher in participants who performed regular physical exercise than in those who did not perform regular physical exercise $\left[5.9 \times 10^{11}(2.5)\right.$ and $5.5 \times 10^{11}(0.9)$, respectively; $P<0.05$ ] (Table 1). Comparison of data on absolute count 
Table 2. Relationship between STAI-I and STAI-II scores with apheresis platelet product quality data $(\mathrm{N}=98)$.

\begin{tabular}{lcccc}
\hline \multicolumn{1}{c}{ Parameters } & STAI-I score & STAI-II score & Absolute count of active platelet & Total platelet count \\
\hline STAI-I score & & & & -0.162 \\
$\quad$ Correlation coefficient & 1.000 & 0.458 & 0.910 & 0.110 \\
$\quad$ Sig. (two tailed) & ND & 0.001 & -0.014 & -0.105 \\
STAI-II score & & & 0.887 & 0.304 \\
$\quad$ Correlation coefficient & 0.458 & 1.000 & 1.000 & 0.091 \\
$\quad$ Sig. (two tailed) & 0.000 & ND & ND & 0.370 \\
Absolute count of active platelet & & & \\
$\quad$ Correlation coefficient & -0.012 & -0.014 & 0.091 & 1.000 \\
$\quad$ Sig. (two tailed) & 0.910 & 0.887 & 0.370 & ND \\
$\quad$ Total platelet count & -0.162 & -0.105 & & \\
$\quad$ Correlation coefficient & 0.110 & 0.304 & & \\
$\quad$ Sig. (two tailed) & &
\end{tabular}

of active platelets and total platelet count according to the lifestyle characteristics of participants are shown in Figs. 3 and 4, respectively.

No significant correlation was found between STAI-I and STAI-II levels of donors and the median value of total platelet counts and active platelet absolute count in the apheresis-platelet concentrates. The significant positive correlation was only found between the STAI-II scores and STAI-I scores of donors (r=0.458, $P=0.001$ ) (Table 2).

\section{DISCUSSION}

The apheresis procedure is a difficult and stressful process for some donors. In some donors who cannot cope with this situation, apheresis process may not be completed. From here, we investigated the possible effect of the stress experienced by some donors and some other personal characteristics on product quality. However, we could not find a significant effect of the parameters that we investigated on the quality of platelet apheresis concentrates.

The studies in the literature only examined the effect of donor's level of anxiety on their decision to become repeat blood donors rather than on the quality of platelet products $[4,5]$. Ringwald et al. [4] suggested that although apheresisplatelet donation was a troublesome and relatively difficult procedure, it was effective in motivating the donors to repeatedly donate blood products.

Various lifestyle factors such as smoking, eating-drinking habits (consumption of alcohol or beverages with caffeine), or performing regular physical exercise may lead to platelet activation [2, 17]. Those factors may also have an effect on the quality of apheresis-platelet products. Scheinichen et al. [2] suggested that smoking was not a factor affecting the quality of apheresis-platelet products; thus, it was not necessary to exclude them from the donor pool in their study. The results from our study also support the results of Scheinichen et al. [2].

The data about the correlation between alcohol con- sumption and platelet activation are very limited [18]. However, other published studies reported some indicators of platelet activation in individuals with acute coronary syndrome and their prognostic values in later processes [19, 20]. A previous study, which used P-selectin (CD62P) as a determinator of platelet activation, examined the correlation between alcohol consumption and platelet activation in individuals with no cardiovascular disease. According to the results of this study; among men, alcohol consumption was inversely associated with activation of platelets, particularly if consumption reached 3-6 drinks per week [18]. In our study, no significant difference was found in the active platelet absolute counts and total product platelet count in the apheresis-platelet concentrates isolated from the donors who consumed and did not consume alcohol.

Physical exercises directly or indirectly affect the platelet functions. Platelets can be activated by increased shear stress and oxidative stress along with elevation of catecholamine levels, especially during acute or tiresome exercise activity [17]. Some epidemiologic studies have been designed to investigate the relationship between exercise and coronary ischemic syndromes through platelet and platelet activation $[21,22]$. One of these studies that investigated the effect of exercise on platelet activation demonstrated that trained participants had a higher number of platelets than sedentary participants, while platelet activation was higher in sedentary participants than in trained participants [22]. In our study, total platelet count of apheresis-platelet products from donors who performed regular physical exercise was significantly higher than that from donors who did not perform regular physical exercise. Results related to platelet count were in agreement with those reported in our study, while those related to platelet activation were not. Selection of different platelet activation markers in these studies may be the reason for this discrepancy.

Secretion of catecholamine, which is a powerful platelet stimulant, increases during emotional stress and anxiety [23, 24]. Because the platelet membrane includes $\alpha-2$ adrenergic receptors, the catecholamine may directly activate the plate- 
lets and cause the release of thromboxane B2, platelet factor 4 (PF4), and beta-thromboglobulin (BTG) [25, 26]. These proteins were also considered as platelet activation markers. In our study, we used flow cytometry analysis to determine platelet activation. In a study executed by Mest et al. [25], the thromboxane B2 levels of the medical school students were measured before and after the exam to show influence of mental stress in man. These measurements were compared with control levels. Accordingly, the thromboxane B2 level after the exam was increased whereas this levels was not changed before the exam. In a study by Levine et al. [26], the association between PF4 and BTG levels and platelet activation was evaluated in a group of healthy individuals before and after delivering a speech. Results showed that the significant increase in both parameters supports the activation of platelets. In our study, it was shown that the donors' level of anxiety did not affect the quality of apheresis-platelet concentrates. This result may be due to the fact that the method used to evaluate platelet activation is different from those employed in other similar studies. Another reason is that the aforementioned studies did not use objective criteria to evaluate anxiety level.

STAI-I and STA-II are frequently used to measure the anxiety level of individuals. When the correlation between STAI-I and STAI-II scores of the donors was examined, a positive significant correlation was found. The values from these scales should be consistent in order to confirm that the tests were performed correctly.

Our study has some limitations. First, demographic features (e.g., age and sex) and frequency or severity of donors' lifestyle characteristics, which we evaluated in this study, was not reflected in the results. The use of an activation criterion in the evaluation of platelet quality is another limitation of this study.

Our results revealed that quality of apheresis-platelets was not affected by both STAI-I and STAI-II levels as well as lifestyle characteristics like smoking, alcohol consumption, and performing regular physical exercise. Therefore, we believe that these issues are not decisive for donor selection. Further studies including female participants and various platelet activation markers are needed to determine the possible effects of donors' anxiety on apheresis-platelet concentrates.

\section{Authors' Disclosures of Potential Conflicts of Interest}

No potential conflicts of interest relevant to this article were reported.

\section{REFERENCES}

1. Yin G, Xu J, Shen Z, Wang Y, Zhu F, Lv H. The relationship of platelet yield, donor's characteristic and apheresis instruments in China. Transfus Apher Sci 2013;49:608-12.

2. Scheinichen D, Heuft HG, Renken C, et al. Impact of tobacco smoking on platelet function in apheresis products in vitro. Vox
Sang 2004;86:252-6.

3. Koudouovoh-Tripp P, Sperner-Unterweger B. Influence of mental stress on platelet bioactivity. World J Psychiatry 2012;2: 134-47.

4. Ringwald J, Lange N, Rabe C, et al. Why do some apheresis donors donate blood just once? Vox Sang 2007;93:354-62.

5. Trimmel M, Lattacher H, Janda M. Voluntary whole-blood donors, and compensated platelet donors and plasma donors: motivation to donate, altruism and aggression. Transfus Apher Sci 2005;33:147-55.

6. National Blood and Blood Components Preparation, Use and Quality Assurance Guide. Ankara, Turkey: Turkish Ministry of Health, 2015. (Accessed February 17, 2019, at http://www. shgm.saglik.gov.tr/TR,9968/ulusal-kan-ve-kan-bilesenleri-hazi rlama-kullanim-ve-kalite-guvencesi-rehberi.html).

7. World Health Organization. Fact Sheet: Physical activity. Geneve, Switzerland: World Health Organization, 2018. (Accessed January 21, 2019, at https://www.who.int/newsroom/fact-sheets/detail/physical-activity).

8. Global Adult Tobacco Survey Collaborative Group. Global Adult Tobacco Survey (GATS): core questionnaire with optional questions, version 2.0. Atlanta, GA: Centers for Disease Control and Prevention, 2010.

9. Ögel K, Tamar D, Özmen E, et al. The frequency of alcohol consumption in Istanbul. Istanbul, Turkey: Kültegin Ögel's Blog, 2003. (Accessed January 21, 2019, at http://www.ogelk.net/ Dosyadepo/istanbul_alkol_yayginlik.pdf).

10. Spielberger CD, Gorsuch RL, Lushene R, Vagg PR, Jacobs GA. The State-Trait Anxiety Inventory (STAI). Palo Alto, CA: Consulting Psychologists Press, 1983.

11. Balsamo M, Romanelli R, Innamorati M, Ciccarese G, Carlucci L, Saggino A. The State-Trait Anxiety Inventory: shadows and lights on its construct validity. J Psychopathol Behav Assess 2013; 35:475-86.

12. Julian LJ. Measures of anxiety: State-Trait Anxiety Inventory (STAI), Beck Anxiety Inventory (BAI), and Hospital Anxiety and Depression Scale-Anxiety (HADS-A). Arthritis Care Res (Hoboken) 2011;63(Suppl 11):S467-72.

13. Oluk S, Ozuredi O, Sakaci T. Determination of state-trait anxiety levels of university students during the learning process of global environmental problems. US-China Education Review 2009;6:49-53.

14. Sevindik CS, Yilmaz MF, Erden SC, Kolat E, Akdeniz M. Is Monday a syndrome? Journal of Mood Disorders 2014;4:152-6.

15. Ahmed N. Quality management procedure of platelet concentrate. Ind J Transfus Med 2016.

16. Gutensohn K, Bartsch N, Kuehnl P. Flow cytometric analysis of platelet membrane antigens during and after continuous-flow plateletpheresis. Transfusion 1997;37:809-15.

17. Heber S, Volf I. Effects of physical (In)activity on platelet function. Biomed Res Int 2015;2015:165078.

18. Mukamal KJ, Massaro JM, Ault KA, et al. Alcohol consumption and platelet activation and aggregation among women and men: the Framingham Offspring Study. Alcohol Clin Exp Res 2005; 29:1906-12.

19. Miyamoto S, Kawano H, Sakamoto T, et al. Formation of platelet microaggregates correlates with adverse clinical outcome in 
patients with coronary artery disease. Thromb Haemost 2003; 89:681-6.

20. Kabbani SS, Watkins MW, Ashikaga T, Terrien EF, Sobel BE, Schneider DJ. Usefulness of platelet reactivity before percutaneous coronary intervention in determining cardiac risk one year later. Am J Cardiol 2003;91:876-8.

21. Powell KE, Thompson PD, Caspersen CJ, Kendrick JS. Physical activity and the incidence of coronary heart disease. Annu Rev Public Health 1987;8:253-87.

22. Singh I, Quinn H, Mok M, et al. The effect of exercise and training status on platelet activation: do cocoa polyphenols play a role? Platelets 2006;17:361-7.

23. Alexander RW, Cooper B, Handin RI. Characterization of the human platelet alpha-adrenergic receptor. Correlation of $[3 \mathrm{H}]$ dihydroergocryptine binding with aggregation and adenylate cyclase inhibition. J Clin Invest 1978;61:1136-44.

24. Weksler BB, Nachman RL. Platelets and atherosclerosis. Am J Med 1981;71:331-3.

25. Mest HJ, Zehl U, Sziegoleit W, Taube C, Forster W. Influence of mental stress on plasma level of prostaglandins, thromboxane B2 and on circulating platelet aggregates in man. Prostaglandins Leukot Med 1982;8:553-63.

26. Levine SP, Towell BL, Suarez AM, Knieriem LK, Harris MM, George JN. Platelet activation and secretion associated with emotional stress. Circulation 1985;71:1129-34. 